Gut, 1979, 20, 6-15

\title{
Light and electron microscopic studies of antibiotic associated colitis in the hamster
}

\author{
C. D. HUMPHREY, W. B. LUShBAUGH, C. W. CONDON, J. C. PITTMAN, \\ AND F. E. PITTMAN ${ }^{1}$ \\ From the Veterans Administration Hospital and the Department of Medicine, Medical University of \\ South Carolina, Charleston, South Carolina, USA
}

SUMMARY Lincomycin and its analogue, clindamycin, are capable of producing mild to severe colonic mucosal injury in humans (antibiotic associated colitis). Patients with the disorder may have severe diarrhoea, pseudomembranous plaques, confluent pseudomembranes, and/or a frank, diffuse haemorrhagic colitis. The present study was designed to assess the Golden Syrian hamster as an animal model for antibiotic associated colitis and to describe lesions seen in the animal model by light, transmission electron, and scanning electron microscopy. A colitis was produced in Golden Syrian hamsters by oral or parenteral administration of lincomycin, clindamycin, or $\mathrm{N}$-demethyl clindamycin. Animals were killed at intervals and microscopic studies made of sequential morphological changes in the ileum, caecum, and colon. The microscopic lesions in the early stages of the disorder were abnormalities within the brush border, cellular oedema, and hyperaemia. Changes in the intracellular organelles were observed in more severely damaged epithelial cells. Epithelial hyperplasia resulted in the piling up of cells on the mucosal surfaces. In specimens with the most severe damage, complete loss of epithelium from the mucosal surface was observed. Pseudomembranous plaques were occasionally seen. Comparison of the clinical, gross, and histological features of the animal disease with the human disorder suggest that, although minor differences are present, the hamster model is suitable for experimental studies of antibiotic associated colitis.

Lincomycin or its analogue, clindamycin, causes colonic mucosal injury in Golden Syrian hamsters with gross and light microscopic features similar to those seen in humans who develop antibiotic associated colitis (AAC) after the use of this and other antibiotics (Humphrey et al., 1974; Pittman et al., 1974; Bartlett et al., 1977; Pittman et al., 1977; Rifkin, 1978). In order further to characterise the hamster model of AAC, animals were treated with oral or parenteral lincomycin, clindamycin, or the $\mathrm{N}$-demethyl metabolite of clindamycin. The pathological changes in colonic mucosa as seen with light, transmission electron, and scanning electron microscopy were determined. Surface features detected by scanning electron microscopy were correlated with light and transmission electron microscopic abnormalities.

${ }^{1}$ Address for reprint requests: Dr F. E. Pittman, Veterans Administration Hospital, 109 Bee Street, Charleston, South Carolina 29403, USA.

Received for publication 10 August 1978

\section{Methods}

PRELIMINARY STUDIES

In all studies, 7-12 week old Golden Syrian hamsters (Sprague Dawley Co., Madison, WI), weighing 90-150 $\mathrm{g}$ and maintained on a diet of Wayne Lab Blox, were used. In preliminary attempts to produce diarrhoea and colitis with lincomycin, four groups of animals were given the drug in their drinking water in concentrations of $0.004-8.0 \mathrm{mg} / \mathrm{ml}(0.4-160$ $\mathrm{mg} / \mathrm{kg} / \mathrm{day}$ ). In this and subsequent experiments, the hamsters were observed daily to determine diarrhoea incidence, general signs of illness, and to measure liquid intake. Intestinal specimens from animals found dead in their cages were not prepared for microscopy. Surviving and control animals were killed and their intestines removed, opened, and examined grossly. Samples of tissue from the ileum, caecum, and ascending colon were taken for histological study. These studies indicated that, when the antibiotic was administered orally in concentrations 
of $0.02 \mathrm{mg} / \mathrm{ml}$ or greater, virtually all animals developed evidence of colitis.

\section{SEQUENTIAL STUDIES}

Fifty-seven Golden Syrian hamsters were given lincomycin in their drinking water at a concentration of $0.04 \mathrm{mg} / \mathrm{ml}$. The average daily dose received by each animal was $4 \mathrm{mg} / \mathrm{kg} /$ day.

At intervals of $29,39,49,56,64,93,99,115$, and 122 hours after initiation of the antibiotic, five randomly selected animals were killed, their intestines removed, opened, and examined grossly. Multiple samples $(1 \times 2 \mathrm{~cm})$ were removed from the ileum, caecum, ascending colon, and sigmoid colon for histological study. Caecal and colonic tissues from 12 lincomycin treated hamsters killed at $29,39,49$, or 64 hours after the initiation of treatment were removed and prepared for scanning electron microscopy. Tissues were also taken from untreated animals at each of the intervals used for the treated animals.

Tissues were fixed in phosphate buffered $3 \%$ glutaraldehyde (Sabatini et al., 1963), pH 7.4 for two hours, rinsed with the same buffer, and postfixed one hour in phosphate buffered $1 \% \mathrm{OsO}_{4}$. Tissues were dehydrated in ethanol, treated with propylene oxide, and embedded in Maraglas (Spurlock et al., 1963), Epon-Araldite (Mollenhauer, 1963), or Epon-812 (Luft, 1961). One to $2 \mu \mathrm{m}$ thick sections were cut with glass knives, stained with toluidine blue (Dawes, 1971) or methylene blue-azure II-basic fuchsin (Humphrey and Pittman, 1974), and examined with a light microscope.

For transmission electron microscopy, thin sections were cut from epoxy embedded specimens with glass knives on an LKB III ultramicrotome, picked up on copper grids, stained with uranyl acetate and lead citrate, and viewed with an Hitachi HS-8, Hitachi HU-12A, or Zeiss 9S-2 electron microscope.

Tissues for scanning electron microscopy were fixed in cacodylate buffered $3 \%$ glutaraldehyde, pH $7 \cdot 2$ and post-fixed in buffered $2 \% \mathrm{OsO}_{4}$ overnight. Tissues were further stabilised by using a thiocarbohydrazide procedure (Kelley et al., 1973). After dehydration in ethanol, tissues were critical point dried from carbon dioxide, mounted on aluminium stubs with silver paint, vacuum coated with gold paladium, and examined at an accelerating voltage of $16 \mathrm{Kv}$ with a field emission Coates and Welter scanning electron microscope.

\section{CLINDAMYCIN AND N-DEMETHYL}

\section{CLINDAMYCIN STUDIES}

Fifty Golden Syrian hamsters were given lincomycin, clindamycin, or $\mathrm{N}$-demethyl clindamycin by the oral or parenteral route. Dosages observed to produce lesions consistently were: lincomycin, $3.5 \mathrm{mg} / \mathrm{kg} /$ day; clindamycin, $6 \mathrm{mg} / \mathrm{kg} /$ day; and $\mathrm{N}$-demethyl clindamycin, $0.4 \mathrm{mg} / \mathrm{kg} /$ day. Eight untreated animals served as controls. The animals were killed at the earliest appearance of illness. No animals found dead in their cages were studied. The abdomen of each animal was opened and tissue samples from the liver, gallbladder, ileum, caecum, ascending and sigmoid colon were removed. Tissue samples were fixed in buffered $10 \%$ formalin, processed with an Autotechnicon, and embedded in paraffin. Samples were also fixed in cacodylate buffered 1.5-1.75\% glutaraldehyde, $\mathrm{pH} 7 \cdot 2$, or phosphate buffered $3 \%$ glutaraldehyde, $\mathrm{pH} 7 \cdot 2$, post-fixed in buffered $1 \%$ $\mathrm{OsO}_{4}$, dehydrated, and embedded in glycol methacrylate (Ruddell, 1967) or epoxy resins (Luft, 1961 ; Mollenhauer, 1963; Spurlock et al., 1963). For light microscopy, paraffin sections were stained with haematoxylin and eosin, or a variety of special stains. Epoxy and methacrylate embedded tissues were sectioned and stained for light and electron microscopy as described above.

\section{Results}

Untreated animals were normal at necropsy. All animals treated with $0.02 \mathrm{mg} / \mathrm{ml}$ or more lincomycin in their drinking water became severely ill within 48-122 hours. Signs of severe illness included non-haemorrhagic diarrhoea ('wet tail'), fur ruffling, and decreased food and water intake. In terminal stages, animals became listless and ceased to move about their cages.

In the sequential studies, clinical signs of illness were not observed until after 64 hours of lincomycin treatment. The guaiac test for occult blood (Searcy, 1969) was performed on faecal pellets, perianal residues (in animals with 'wet tail'), and caecal contents of selected treated and control animals. Neither occult nor grossly visible blood was observed in the faecal pellets of any of these animals. However, grossly visible or occult blood was detected in caecal contents and perianal residues of some treated animals. Caecal contents from untreated hamsters were non-reactive to the guaiac test.

Gross tissue abnormalities in treated hamsters were first seen at necropsy after 49 hours of lincomycin administration. Areas of focal mucosal haemorrhage were present in the caecum. Some animals on the drug for longer periods had diffuse haemorrhage, watery caecal contents, mucosal oedema, and gaseous distention of the ileum and caecum. Occasionally, hyperaemia was seen in the terminal ileum and ascending colon.

An attempt was made to classify intestinal ab- 
normalities observed by light microscopy as mild, moderate, or severe. Mild changes included submucosal and mucosal oedema and hyperaemia, minimal increase in numbers of round cells in the lamina propria and minimal abnormalities of surface epithelium including hyperplasia and vesiculation (Fig. 1). Oedema in the mucosa was often focal and located just beneath the surface epithelium, at times lifting the cells away from their basal attachment. Moderate changes were characterised as more pronounced submucosal and focal mucosal oedema and hyperaemia with frank haemorrhage into the lamina propria (Fig. 2). Marked and extensive surface epithelial hyperplasia and vesiculation (Fig. 2 ), and focal ulceration, at times with exudation of round cells, erythrocytes, and fibrin from the lamina propria into the gut lumen (Fig. 3) were also seen. Severe changes included all those classified as moderate, with the addition of extensive surface epithelial cell ulceration (Fig. 4). Most specimens had a spectrum of abnormalities, especially those considered mild to moderate, regardless of length of treatment.

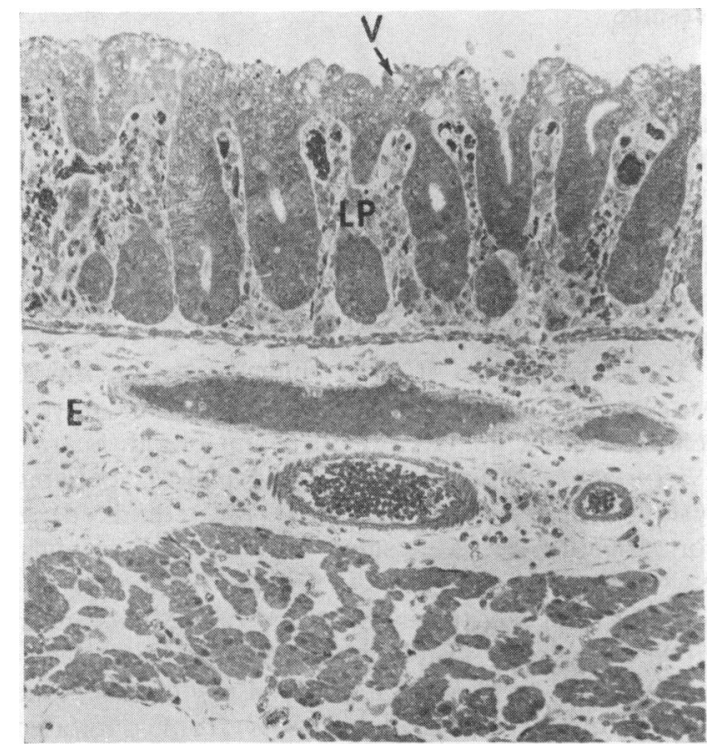

Fig. 1 Caecum of a lincomycin treated hamster. There is marked submucosal oedema $(E)$ and pronounced hyperaemia in the submucosa and lamina propria $(L P)$. The surface epithelium is vacuolated $(V)$. Methylene blue-basic fuchsin, $\times 85$. (Original magnification quoted in this and following Figures.)

A progression of AAC lesions was seen. Animals that were killed at 29 and 39 hours after initiation of treatment had infrequent mild histopathological findings. Animals killed at 49-64 hours had moderate

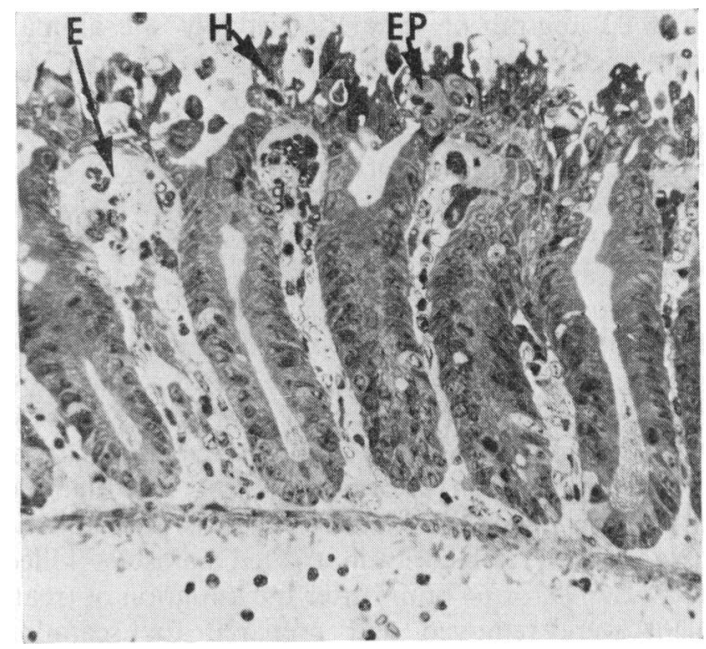

Fig. 2 Caecum of a hamster treated with $0.04 \mathrm{mg} / \mathrm{ml}$ lincomycin and killed after 49 hours. Hyperaemia and oedema $(E)$ are seen in the lamina propria. The surface epithelium (EP) exhibits marked hyperplasia $(H)$. These epithelial cells have lost their columnar shape and the basal orientation of nuclei. Methylene blue-basic fuchsin, $\times 205$.

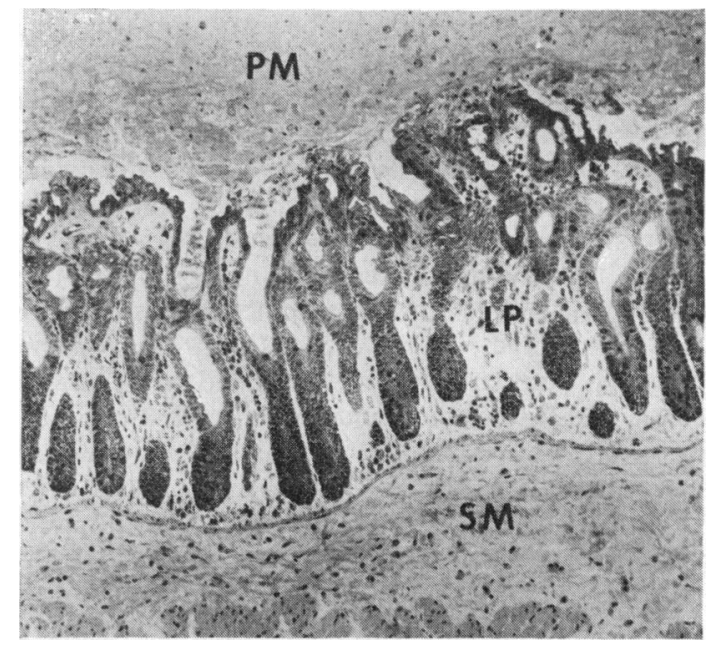

Fig. 3 Hamster caecum from an animal receiving $0.02 \mathrm{mg} / \mathrm{ml}$ lincomycin. The mucosa is markedly thickened by oedema in the submucosa (SM) and lamina propria $(L P)$. Mucus, fibrin, and inflammatory cells exuding from micro-ulcerated epithelium form a pseudomembrane-like structure $(P M)$. Toluidine blue, $\times 85$.

to severe caecal lesions. Severe caecal lesions predominated after approximately four days of lincomycin treatment $(93,99,115$, and 122 hours).

Gross and light microscopic findings in hamsters 


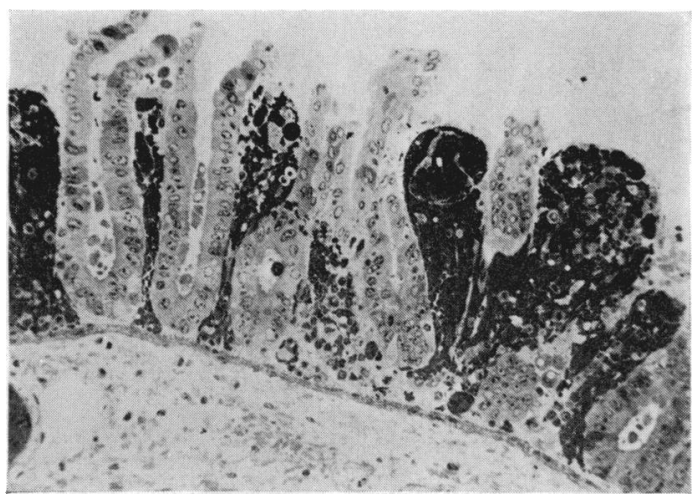

Fig. 4 Caecum of a hamster treated with $0.04 \mathrm{mg} / \mathrm{ml}$ lincomycin for 122 hours. The surface epithelium is partially denuded and there is marked haemorrhage into the lamina propria. Methylene blue-basic fuchsin, $\times 165$.

treated with clindamycin and $\mathrm{N}$-demethyl clindamycin were identical to those found in animals treated with lincomycin. The caecum was the site of earliest involvement and was the most commonly and severely affected portion of the intestine in animals receiving any of the three antibiotics. Similar ultrastructural abnormalities were present in other affected portions of the intestine. For these reasons, caecal mucosal lesions are illustrated here. Abnormal findings were not seen in the liver or gallbladder of control animals or animals receiving any of the three antibiotics.

Scanning electron microscopic examination of caecal mucosa of normal hamsters revealed a convoluted surface which was punctuated at intervals by slight depressions containing mucus from underlying goblet cells (Fig. 5a). The undulation and infolding of normal caecal mucosa was confirmed by light microscopy (Fig. 5b). Higher magnification scanning electron microscopy revealed the tips of the individual microvilli, goblet cell mucus, and bacteria (Fig. 6). Examination of the normal columnar principal cells of the epithelium by transmission electron microscopy (Fig. 7) showed that they had an orderly microvillous border on which a glycocalyx could be demonstrated. These cells contained basal nuclei, perinuclear Golgi, rough endoplasmic reticulum, small vacuoles, and many mitochondria. Epithelial cells were closely joined by desmosomes at their lateral borders.

Increased numbers of spherical structures ('round bodies') in the microvillous border of the intestinal epithelium were demonstrated with transmission electron microscopy in some animals at early stages of the disorder (Fig. 8). At later stages, some cells had microvilli which were distorted, irregular in length, tufted or totally lost (Figs. 9, 10). Pronounced

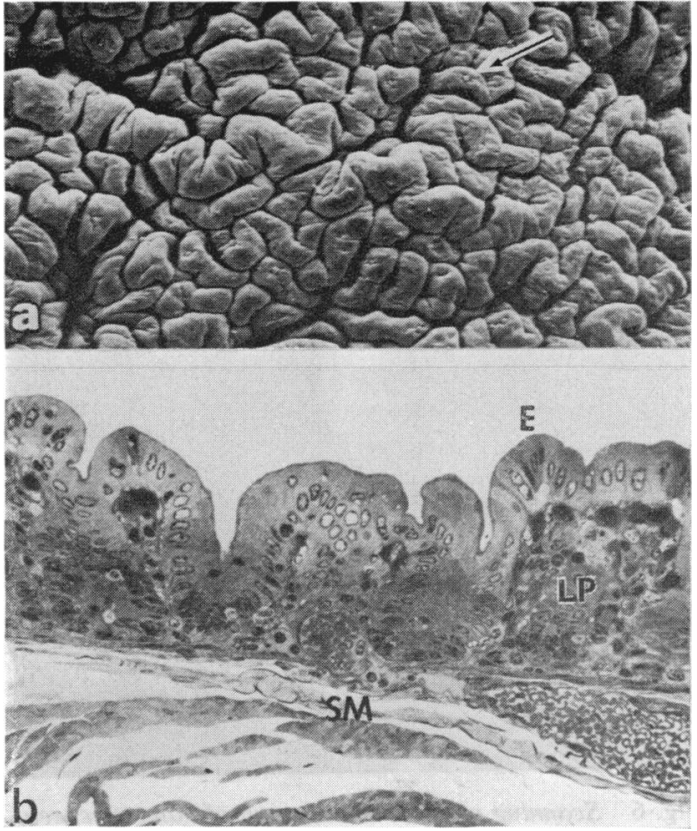

Fig. 5(a) Scanning electron micrograph of hamster caecal mucosa from an untreated animal. The mucosa is composed of convoluted folds. The smooth surface is interrupted by small depressions containing mucus secreted from underlying goblet cells (arrow). $\times 75$. (b) Light micrograph of hamster caecal mucosa from an untreated animal. The thin mucosa is lined by columnar epithelium $(E)$ which covers the lamina propria $(L P)$ and submucosa $(S M)$. Toluidine blue, $\times 210$.

cellular oedema of surface epithelium appeared as large intracellular vacuoles (Figs. 1, 11). Intracellular oedema caused a bulging of the apical cell surface (Fig. 11). In some cells, oedema fluid was present within the terminal web, resulting in displacement of the microvillous border (Fig. 12). Cells examıned by scanning electron microscopy bulged into the lumen and were distinctly separated from one another (Fig. 13). Microvilli on these cells were often distorted, irregular in length, tufted, or absent (Figs. $10,13)$. Oedematous cells had compressed mitochondria with increased intercristal spaces. Increased ergastoplasmic spaces were present between cisternae of the rough endoplasmic reticulum (Fig. 12). Intraepithelial flagellates, probably Trichomonas $s p$, were seen occasionally within damaged epithelium (Fig. 10).

In more severely damaged tissue, an accumulation of damaged epithelial cells was often seen at the mucosal surface (Fig. 14). This finding was interpreted as resulting from hyperplasia of the mucosal epithelium. Epithelial hyperplasia was seen by 


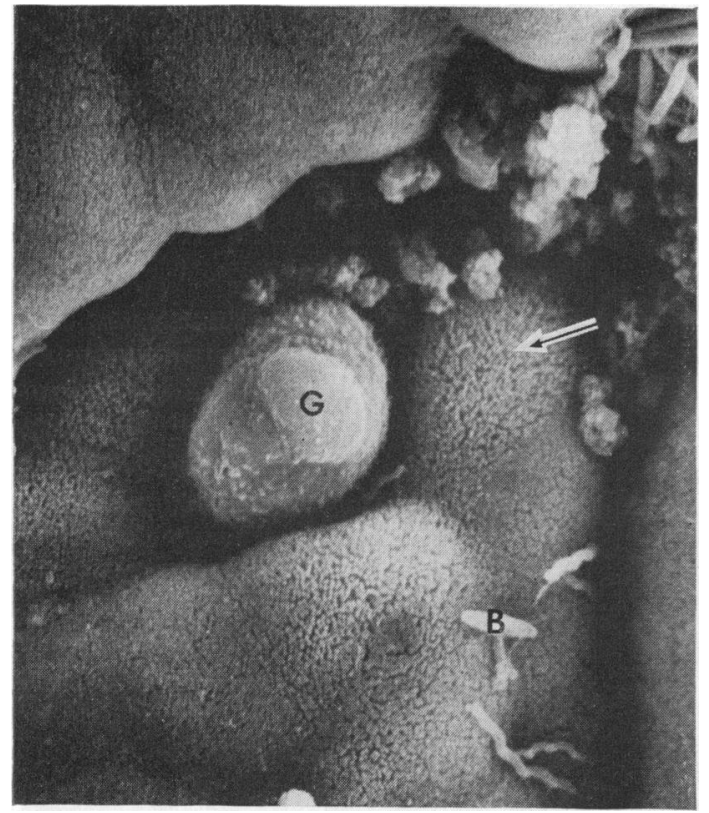

Fig. 6 Scanning electron micrograph of hamster caecal mucosa from an untreated animal. Tips of microvilli (arrow) and bacteria $(B)$ are present on the mucosal surface. Mucin can be seen exuding from the apical surface of a goblet cell $(G) . \times 3200$.

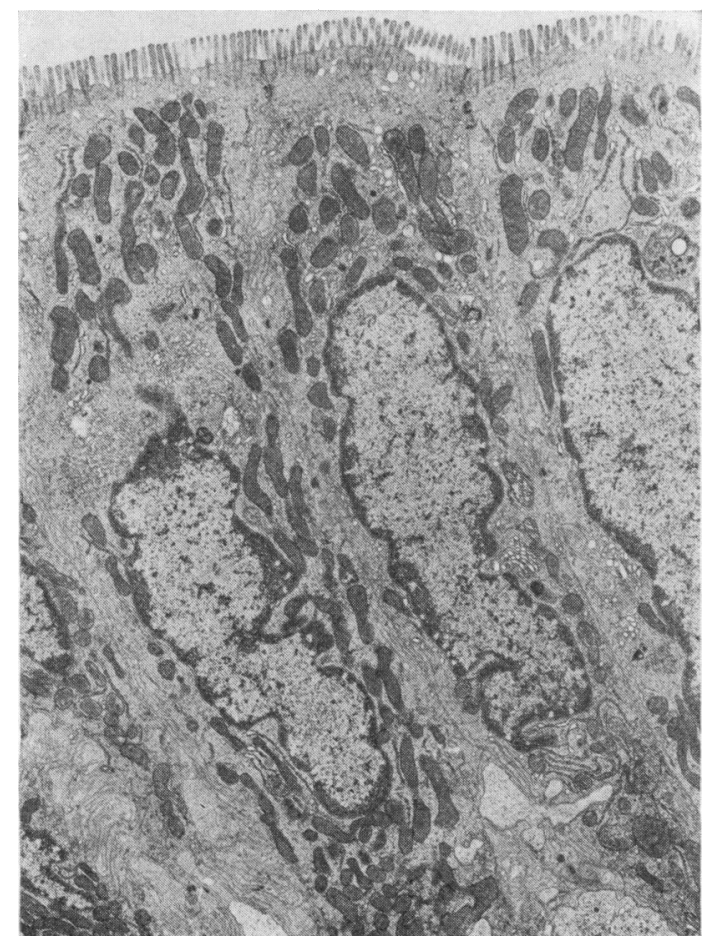

Fig. 7 Transmission electron micrograph of hamster caecal mucosa from an untreated animal. $\times 4200$.

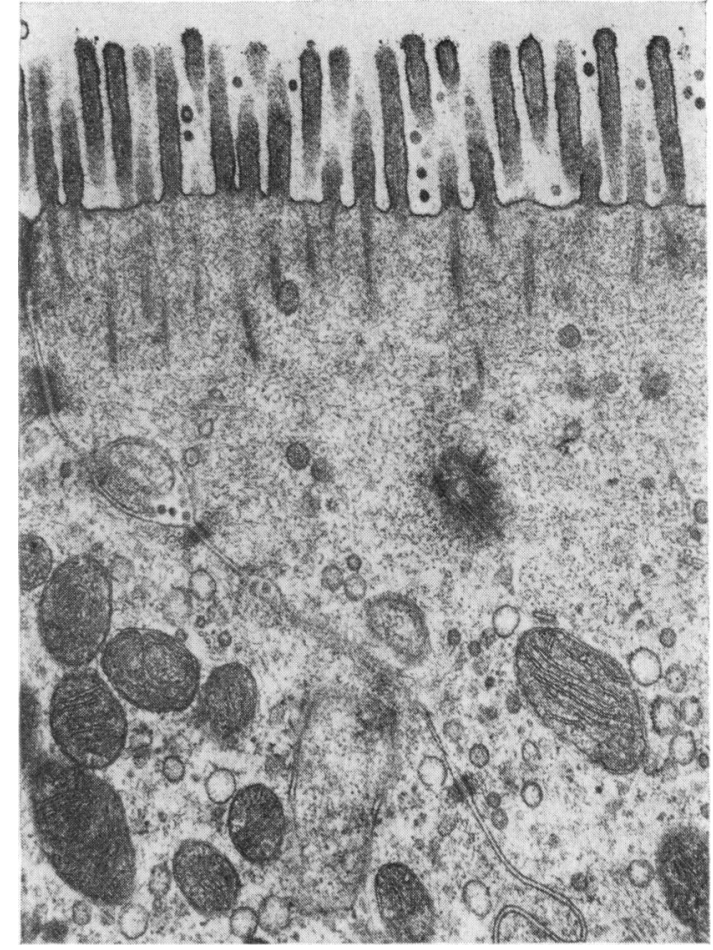

Fig. 8 Transmission electron micrograph of the apical portion of an epithelial cell from the mucosa of $a$ hamster receiving lincomycin for 23 hours (early stage of the disorder). Note the presence of 'round bodies' or spherical structures among the microvilli. $\times 20000$.

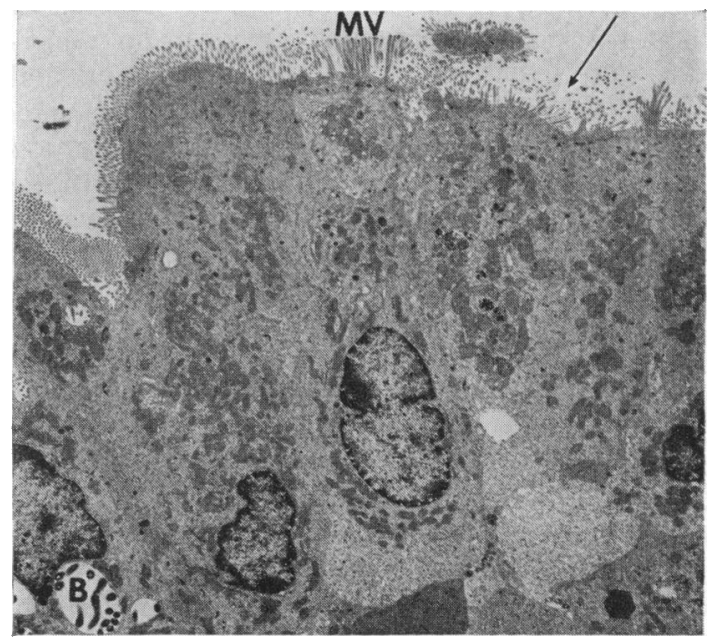

Fig. 9 Transmission electron micrograph of tissue from a hamster treated with clindamycin. Many of the microvilli $(M V)$ are tufted and elongated. There are areas of the surface in which the microvilli are denuded (arrow). $\times 2300$. 


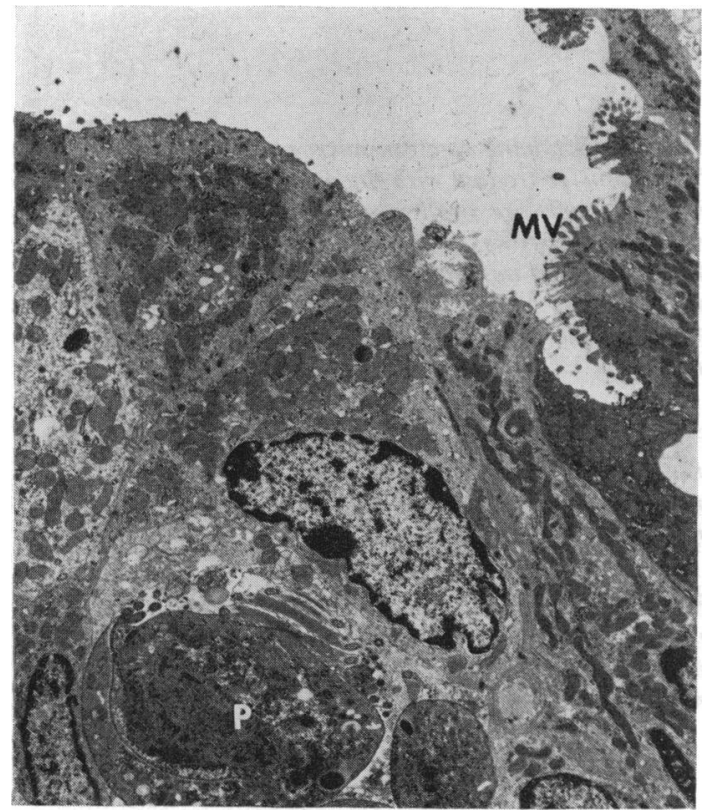

Fig. 10 Transmission electron micrograph of mucosa from a hamster treated with lincomycin. Some cells are pale staining. The epithelium occasionally contains protozoa $(P)$. Microvilli $(M V)$ are abnormally shortened, few in number or absent. $\times 5500$.

Fig. 11 Transmission electron micrograph of tissue from a hamster treated with clindamycin. The swollen cells protrude into the lumen, have pale staining cytoplasm, and extensive vacuolisation. $\times 3700$.

Fig. 12 Transmission electron micrograph of epithelial cells from a hamster treated with clindamycin. Portions of the terminal web are filled with fibrillar and amorphous materials which force the microvilli (MV) away from the cell surface. The endoplasmic reticulum $(E R)$ is swollen and the mitochondria $(M)$ are crenated. $\times 4600$.

Fig. 10

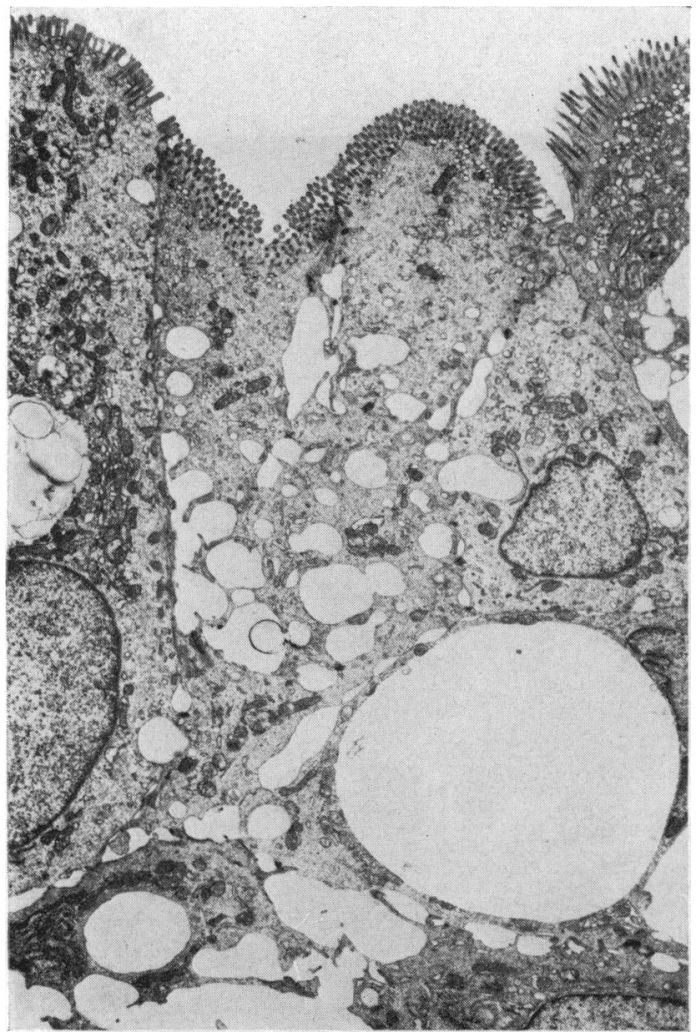

Fig. 11

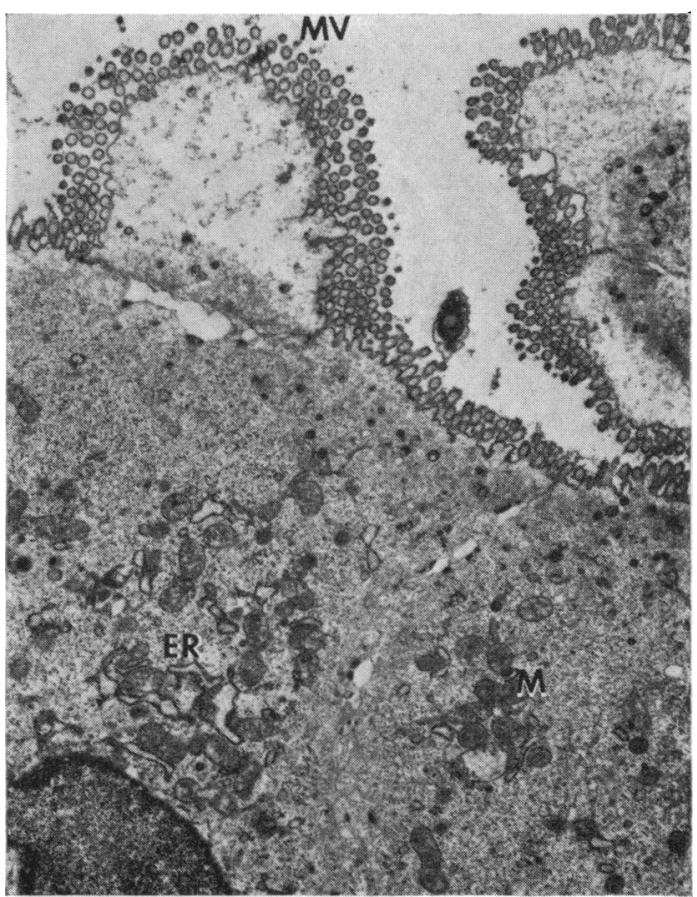

Fig. 12 


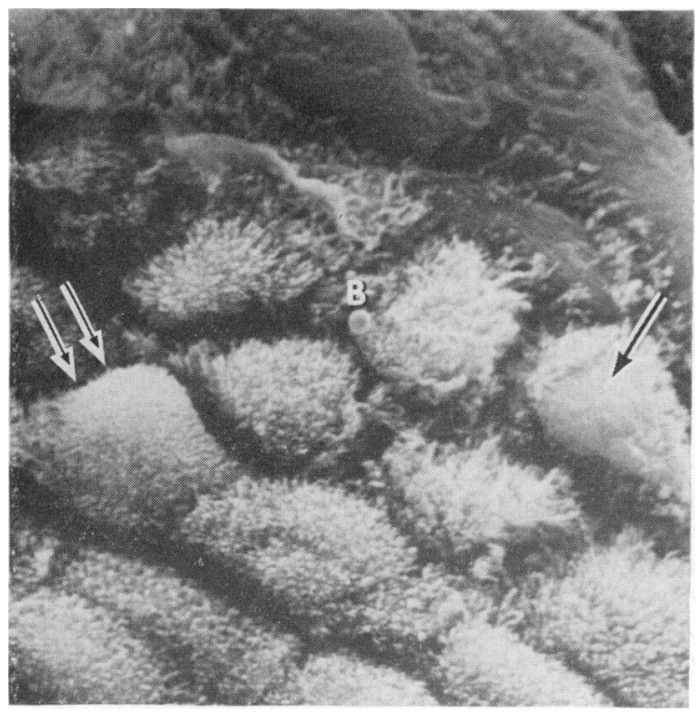

Fig. 13

Fig. 13 Scanning electron micrograph of mucosa from hamster treated with lincomycin. Individual epithelial cells are swollen and separated from adjacent cells (small arrows). The microvilli are irregularly distributed and misshapen. Blebs (B) formed by microvilli are present in some areas. In other areas, the microvilli are lost from the cell surfaces (large arrow). $\times 3700$.

Fig. 14 Light micrograph of mucosa from a hamster treated with lincomycin. Surface epithelial hyperplasia (arrow), submucosal and subepithelial oedema are present. Toluidine blue, $\times 275$.

Fig. 15 Scanning electron micrograph of tissue from a hamster treated with lincomycin. Epithelial cells are loosely attached to the luminal surface of the mucosal folds. $\times 320$.

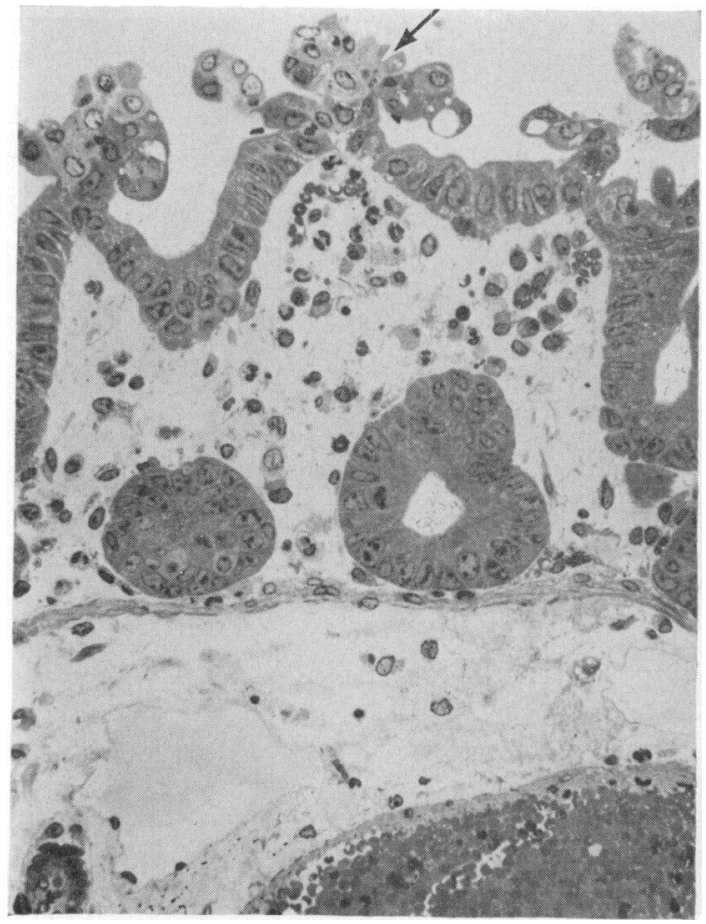

Fig. 14

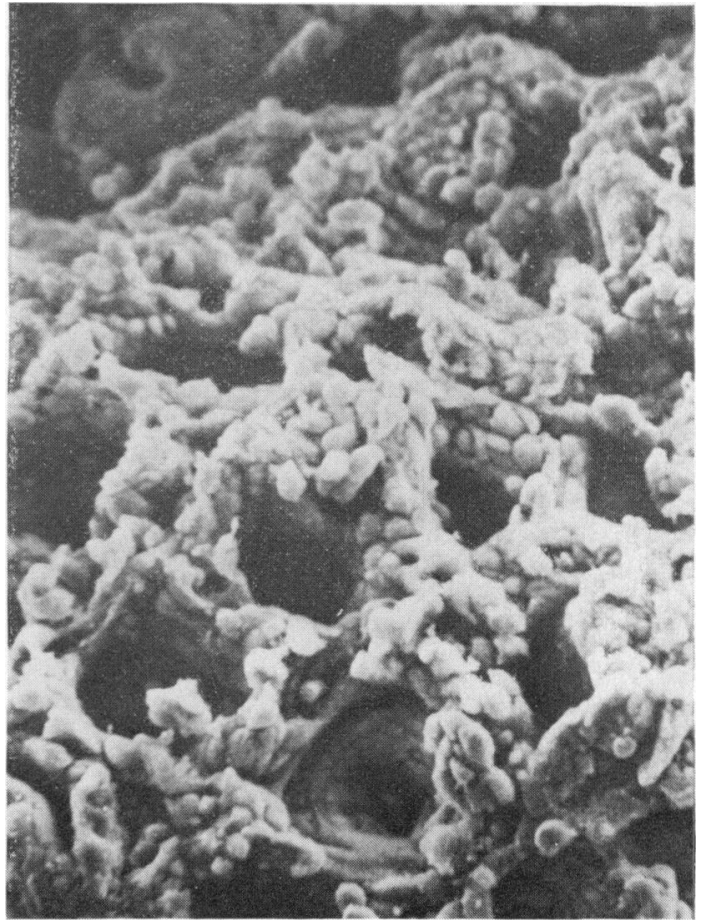

Fig. 15 
scanning electron microscopy as rounded cells loosely attached along the upper surface of the mucosal folds (Fig. 15). Marked oedema and mildly increased cellularity of the lamina propria and submucosa due to infiltration of polymorphonuclear leucocytes, plasma cells, or lymphocytes were also noted. The lamina propria became exposed to the intestinal content when severely damaged epithelial cells were lost from luminal surfaces. Epithelial cells were often retained within the mucosal folds or crypts (Figs. 4,16 ). In some preparations of severely damaged tissue, epithelial cells could be seen extruded from the crypts as intact cores of cells (Fig. 16).

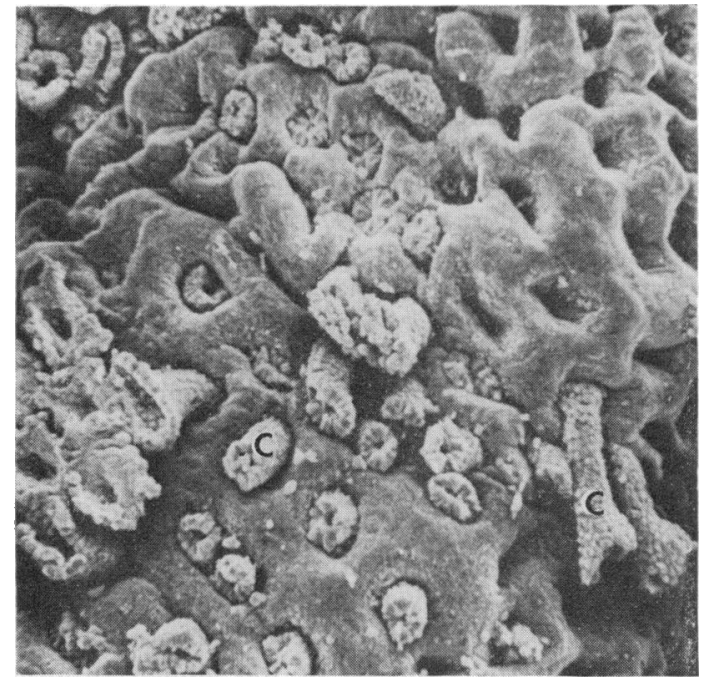

Fig. 16 Scanning electron micrograph of mucosa from a hamster treated with lincomycin. Cores of epithelial cells $(C)$ remain loosely attached within the crypts. Some cores have fallen from the openings and lie upon the denuded la nina propria. $\times 140$.

Gross pseudomembranous lesions were infrequently seen in focally haemorrhagic areas of the caecum of lincomycin treated hamsters (Fig. 17). Caecal mucosa peripheral to these haemorrhagic foci was reddened and oedematous. By light microscopy, pseudomembranous plaques (Figs. 3, 18) were formed by streaming of material from the lamina propria into the lumen from micro-ulcerations in the mucosal epithelium. Pseudomembranous lesions contained erythrocytes, inflammatory cells, bacteria, and sloughed epithelial cells bound together by fibrin. The presence of fibrin in the pseudomembranes was confirmed by phosphotungstic acid-haematoxylin staining and by electron microscopy.

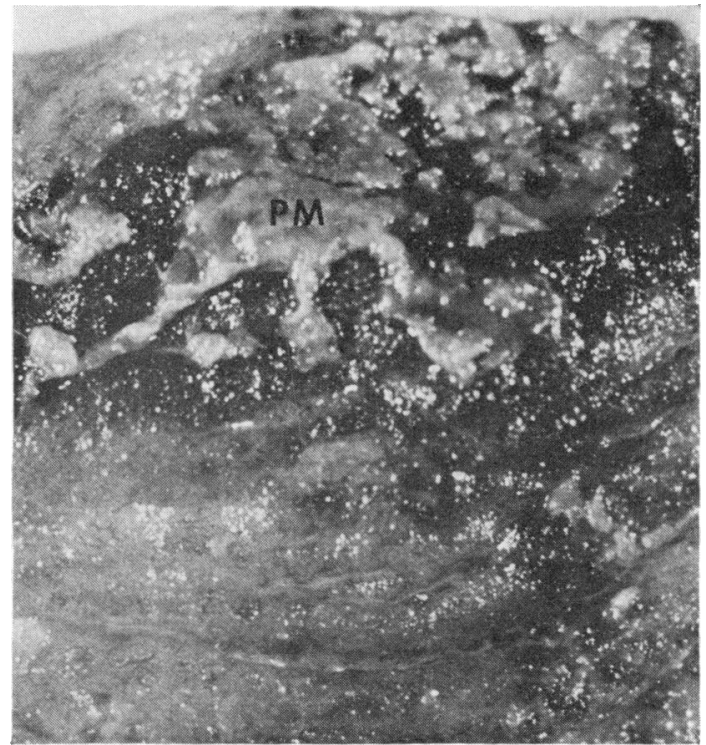

Fig. 17 Gross appearance of a portion of a caecal specimen from a hamster receiving $24 \mathrm{mg} / \mathrm{kg} /$ day lincomycin parenterally for two days. The mucosa is thickened, oedematous, and has an adherent confluent pseudomembrane (PM). Haemorrhagic foci are present in the area of the pseudomembrane. $\times 6.6$.

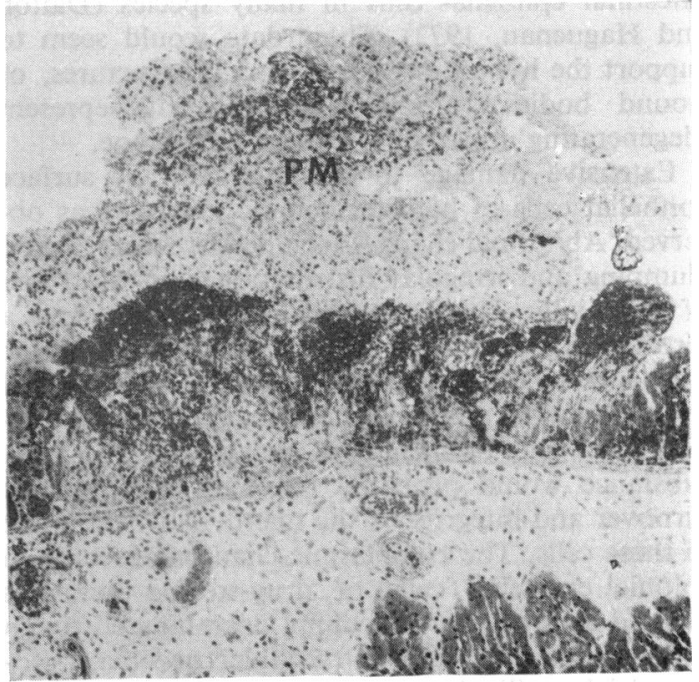

Fig. 18 Light micrograph of lesions seen in a hamster treated with $N$-demethyl clindamycin. $A$ pseudomembranous plaque is formed by exudation of cells and fluid from the lamina propria through a micro-ulceration in surface epithelium. Haematoxylin and eosin, $\times 80$. 


\section{Discussion}

In the present study, it was observed that the light and electron microscopic appearance of hamster intestine after treatment with clindamycin or $\mathrm{N}$ demethyl clindamycin was comparable with that seen after treatment with lincomycin. The light and transmission electron microscopic appearance of hamster caecal mucosa after treatment with either clindamycin or lincomycin was similar to that of sigmoid colonic biopsy material from patients with AAC who had taken either drug (Humphrey et al., 1974; Pittman et al., 1974, 1977).

Increased numbers of spherical structures ('round bodies') were seen in the microvillous border of hamsters and humans with AAC. These were apparently the same structures interpreted by Steer (1975) to be viruses. However, these 'round bodies' have been seen in colonic epithelium of normal and germ-free animals (Pittman and Pittman, 1966; Humphrey et al., 1973; Chandler et al., 1975; Dougherty, 1976), as well as in disease states not thought to have a viral aetiology (Tomkins et al., 1975). The membrane of the spherical structures has a glycocalyx identical with that of the microvilli and its acid phosphatase activity is also similar (Humphrey et al., 1973). The particles believed by Steer (1975) to be viruses in cytoplasmic vacuoles appear to be inclusions within multivesicular or residual bodies. These vacuoles are a normal feature of intestinal epithelial cells in many species (Dalton and Haguenau, 1973). These data would seem to support the hypothesis that spherical structures, or 'round bodies', are not viruses, but represent 'degenerating' microvillar plasma membrane.

Extensive damage to the microvilli of surface epithelial cells of hamster colonic mucosa was observed. Abnormal changes included irregular length, clumping and irregular distribution, and focal loss of microvilli. These abnormalities could reflect a direct effect on microvillar membranes of a toxic substance in the gut lumen, or could have resulted from deranged epithelial cell metabolism. Disruption of hamster epithelial cell metabolism by a toxic substance would probably have an effect on the turnover and integrity of the microvillar membrane of these cells. The cytoplasmic changes observed in colonic epithelial cells of drug-treated hamsters (dilated endoplasmic reticulum, degranulated rough endoplasmic reticulum, intracellular oedema, mitochondrial swelling) are consistent with the action of a cytotoxin which interferes with some phase of intracellular metabolism. Similar alterations were seen by Trump and Arstila (1975) in cells treated with chemical agents. Epithelial hyperplasia was a predominant feature of the mucosal response in humans (Pittman et al., 1974, 1977) and hamsters after treatment with lincomycin, clindamycin, or $\mathrm{N}$-demethyl clindamycin. Hyperplasia resulted in the piling up of epithelial cells at the luminal surface of the mucosa. Hyperplasia may be a compensatory response to severe surface epithelial damage. The compensatory mechanism may be comparable with that described in ischaemic damage to intestinal epithelium (Rijke et al., 1976). Scanning electron microscopy of the severely damaged mucosa revealed complete loss of surface epithelium and demonstrated that the remaining crypt epithelium is shed as intact cores. This suggests that epithelial replacement was not adequate in severely damaged areas of the mucosa.

In some cases of human antibiotic associated colitis, a diffuse and occasionally haemorrhagic colitis with bloody diarrhoea may occur. In others, a colitis exhibiting pseudomembranous lesions (plaques and confluent pseudomembranes) with bloody or nonbloody diarrhoea has been described (Stroehlein et al., 1974; Viteri et al., 1974; Pittman et al., 1974, 1977). These two subtypes of AAC seen in humans have parallels in the animal model. The sequential pathological changes observed in the epithelium of treated hamsters suggest an explanation for the occurrence of two subtypes of AAC seen in humans after antibiotic therapy. The surface epithelium appears to be the initial site of injury. Damage to these cells stimulates increased mitosis in crypt epithelium. When cellular injury is severe and/or the cause of the injury is sustained, focal or diffuse epithelial ulceration would occur. If the injury is focal, micro-ulcerations can result through which exudation of the contents of the lamina propria follows. Plaques could be formed when this exudate contains sufficient fibrin. Adjacent plaques coalesce to form a confluent pseudomembrane. Plaques could be removed during or after formation through the action of mucosal and/or luminal fibrinolysins. On the other hand, if the epithelial surface is extensively sloughed, a diffuse haemorrhagic colitis would result. If the epithelial damage is relatively mild, neither focal nor extensive ulceration would occur, but severe functional disturbances would be expected. In this instance, the clinical picture would be 'simple diarrhoea' without bleeding or endoscopic evidence of colitis.

There is increasing evidence that a bacterial toxin is responsible for the diarrhoea and mucosal injury in both human AAC (Larson et al., 1977; Larson and Price, 1977; Rifkin et al., 1977; Bartlett et al., 1978) and in the animal model (Bartlett et al., 1977; Humphrey et al., 1978; Katz et al., 1978; Rifkin et al., 1978). The appearance of hamster colonic mucosa after treatment with lincomycin, clinda- 
mycin, or $\mathrm{N}$-demethyl clindamycin, as presented here, is consistent with the hypothesis that the pathological features of the disease are dependent on the action of a toxic substance on surface epithelium. Further studies with the hamster model should provide better understanding of the pathogenesis of antibiotic associated colitis and may lead to a satisfactory method of preventing this adverse drug reaction.

This study was supported in part by grants from The John A. Hartford Foundation, Inc., New York, New York; The Upjohn Company, Kalamazoo, Michigan; the Medical Research Service of the Veterans Administration; and The Roche Foundation for Medical Research. The authors wish to thank Dr Gordon Hennigar and Dr Harvey Bank for providing extensive use of the scanning electron microscope used in this study. The encouragement and support of Dr Joseph C. Ross is gratefully acknowledged.

\section{References}

Bartlett, J. G., Onderdonk, A. B., Cisneros, R. L., and Kasper, D. L. (1977). Clindamycin-associated colitis due to a toxin-producing species of Clostridium in hamsters. Journal of Infectious Diseases, 136, 701-705.

Bartlett, J. G., Chang, T. W., Gurwith, M., Gorbach, S. L., and Onderdonk, A. B. (1978). Antibiotic-associated pseudomembranous colitis due to toxin-producing clostridia. New England Journal of Medicine, 298, 531-534.

Chandler, R. L., Bird, R. G., and Bland, A. P. (1975). Particles associated with microvillous border of intestinal mucosa (Letter). Lancet, 2, 931-932.

Dalton, A. J., and Haguenau, F., eds. (1973). Ultrastructure of Animal Viruses and Bacteriophages: An Atlas, pp. 391397. Academic Press: New York.

Dawes, C. J. (1971). Biological Techniques in Electron Microscopy. Barnes and Noble: New York.

Dougherty, W. J. (1976). Microblebs of intestinal epithelial cell microvilli of Citellus tridecemlineatus. Anatomical Record, 185, 77-83.

Humphrey, C. D., and Pittman, F. E. (1974). A simple methylene blue-azure II-basic fuchsin stain for epoxy embedded tissue sections. Stain Technology, 49, 9-14.

Humphrey, C. D., Pittman, F. E., and Pittman, J. C. (1973). Ultrastructural and enzymic characteristics of intestinal microvillous round bodies. Journal of Cell Biology, 59, 153a (Abstract).

Humphrey, C. D., Pittman, J. C., and Pittman, F. E. (1974). A hamster model for lincomycin colitis. Gastroenterology, 66, 847 (Abstract).

Humphrey, C. D., Condon, C. W., Cantey, J. R., and Pittman, F. E. (1978). Partial purification of a toxin found in hamsters with antibiotic associated colitis (AAC): reversible binding of the toxin by cholestyramine (Abstract). Gastroenteroiogy, 74, 1046.

Katz, L., LaMont, J. T., Trier, J. S., Sonnenblick, E. B., Rothman, S. W., Broitman, S. A., and Rieth, S. (1978). Experimental clindamycin-associated colitis in rabbits: evidence for toxin-mediated mucosal damage. Gastroenterology, 74, 246-252.
Kelley, R. O., Dekker, R. A., and Bluemink, J. G. (1973). Ligand-mediated osmium binding: its application in coating biological specimens for scanning electron microscopy. Journal of Ultrastructure Research, 45, 254-258.

Larson, H. E., Parry, J. V., Price, A. B., Davies, D. R., Dolby, J., and Tyrrell, D. A. J. (1977). Undescribed toxin in pseudomembranous colitis. British Medical Journal, 1, 1246-1248.

Larson, H. E., and Price, A. B. (1977). Pseudomembranous colitis: presence of clostridial toxin. Lancet, 2, 1312-1314.

Luft, J. H. (1961). Improvements in epoxy resin embedding methods. Journal of Biophysical and Biochemical Cytology, 9, 409-414.

Mollenhauer, H. H. (1963). Plastic embedding mixtures for use in electron microscopy. Stain Technology, 39, 111-114.

Pittman, F. E., and Pittman, J. C. (1966). An electron microscopic study of the epithelium of normal human sigmoid colonic mucosa. Gut, 7, 644-661.

Pittmann, F. E., Pittman, J. C., and Humphrey, C. D. (1974). Colitis following oral lincomycin therapy. Archives of Internal Medicine, 134, 368-372.

Pittman, F. E., Norgaard, R. P., Shelley, W. M., and Hennigar, G. R. (1977). The spectrum of sigmoidoscopic findings and histopathology in lincomycin/clindamycin colitis. In Symposium/Workshop on Epidemiological Issues in Reported Drug-Induced Illnesses: SMON and Other Examples. McMaster University Library Press: Ontario. (In press.)

Rifkin, G. D., Fekety, F. R., Silva, J., Jr., and Sack, R. B. (1977). Antibiotic-induced colitis: implication of a toxin neutralised by Clostridium sordellii antitoxin. Lancet, 2, 1103-1106.

Rifkin, G. D. Silva, J., Jr., and Fekety, R. (1978). Gastrointestinal and systemic toxicity of fecal extracts from hamsters with clindamycin-induced colitis. Gastroenterolog. $14,52-57$.

Rijke, R. P. C., Hanson, W. R., Plaisier, H. M., and Osborne, J. W. (1976). The effect of ischemic villus cell damage on crypt cell proliferation in the small intestine. Evidence for a feedback control mechanism. Gastroenterology, 71, 786792.

Ruddell, C. L. (1967). Embedding media for 1-2 micron sectioning. 2. Hydroxyethyl methacrylate combined with 2-butoxyethanol. Stain Technology, 42, 253-255.

Sabatini, D. D., Bensch, K., and Barrnett, R. J. (1963). Cytochemistry and electron microscopy: the preservation of cellular ultrastructure and enzymatic activity by aldehyde fixation. Journal of Cell Biology, 17, 19-58.

Searcy, R. L. (1969). Diagnostic Biochemistry, p. 277. McGraw-Hill: New York.

Spurlock, B. O., Kattine, V. C., and Freeman, J. A. (1963). Technical modifications in Maraglas embedding. Journal of Cell Biology, 17, 203-207.

Steer, H. W. (1975). The pseudomembranous colitis associated with clindamycin therapy-a viral colitis. Gut, 16, 695-706.

Stroehlein, J. R., Sedlack, R. E., Hoffman, H. N., II, and Newcomer, A. D. (1974). Clindamycin-associated colitis. Mayo Clinic Proceedings, 49, 240-243.

Tomkins, A. M., Wright, S. G., Bird, R. G., and James, W. P. T. (1975). Virus-like particles in jejunal mucosa. Lancet, 2, 36-37.

Trump, B. F., and Arstila, A. U. (1975). Cellular reaction to injury. In Principles of Pathobiology, 2nd ed., pp.9-96. Edited by M. F. La Vi aand R. B. Hill, Jr. Oxford University Press: New York.

Viteri, A. L., Howard, P. H., and Dyck, W. P. (1974). The spectrum of lincomycin-clindamycin colitis. Gastroenterology, 66, 1137-1144. 